Tropical Journal of Pharmaceutical Research June 2012; 11 (3): 429-435

(C) Pharmacotherapy Group,

Faculty of Pharmacy, University of Benin

Benin City, 300001 Nigeria.

All rights reserved.

Available online at http://www.tjpr.org

Research Article

http://dx.doi.org/10.4314/tjpr.v11i3.12

\title{
Aqueous Bark Extract of Cinnamomum Zeylanicum: A Potential Therapeutic Agent for Streptozotocin- Induced Type 1 Diabetes Mellitus (T1DM) Rats
}

\author{
Syed A Hassan ${ }^{1^{*}}$, Ritu Barthwal ${ }^{2}$, Maya S Nair ${ }^{2}$ and Syed S Haque \\ ${ }^{1}$ Department of Biotechnology, Institute of Life Sciences, University of Hyderabad Campus, Hyderabad, ${ }^{2}$ Molecular \\ Biophysics Laboratory, Department of Biotechnology, Indian Institute of Technology Roorkee, Roorkee, ${ }^{3}$ Department \\ of Clinical Biochemistry, Indira Gandhi Institute of Medical Sciences, Patna, India.
}

\begin{abstract}
Purpose: To investigate the anti-diabetic, hepatoprotective and lipid homeostatic activity of Cinnamomum zeylanicum aqueous bark extract on streptozotocin (STZ)-induced type-I diabetic rats.

Methods: The animals were divided into three groups $(n=6)$. of normal rats; streptozotocin-induced diabetic rats; and diabetic rats treated with $200 \mathrm{mg} / \mathrm{kg}$ of the aqueous bark extract, respectively. Treatment was via the oral route for 15 days. Various biochemical parameters, including lipid profile and glycogen biosynthesis were analysed. Similarly, differential regulation and expression of glucose homeostatic enzymes were evaluated in order to validate the anti-diabetic activity of the extract.

Results: Total cholesterol (TC), triglyceride (TG), LDL-cholesterol (LDL) and VLDL-cholesterol (VLDL) levels decreased significantly $(p<0.05)$ in the diabetic animals by 12.5, 23.86, 14.96 and $20 \%$, respectively, compared to their initial values. The extract increased HDL-cholesterol (HDL) and tissue glycogen levels by 25.0 and $172.3 \%$, respectively, in diabetic rats. Similarly, differential regulation and expression of glucose homeostatic enzymes, namely, glucokinase (GK), glucose-6-phosphatase (G6Pase), phosphoenol pyruvate carboxykinase (PEPCK), glucose-6-phosphate dehydrogenase (G-6$P D H)$ and Insulin II (Ins II), showed significant improvement upon extract treatment in STZ-induced diabetic rats.

Conclusion: These results demonstrate the anti-diabetic, and hypolipidemic activities of Cinnamomum zeylanicum aqueous bark extract in diabetic rats.
\end{abstract}

Keywords: Streptozotocin, Type 1 diabetes mellitus, Cinnamomum zeylanicum, Glucose homeostasis, Hypoglycemia, Lipid homeostasis. 


\section{INTRODUCTION}

During the last decades of the $20^{\text {th }}$ century, there was an increase in the incidence of Type 1 diabetes mellitus (T1DM) with several million people already affected around the globe. A variety of factors, ranging from immune dysregulation to environmental triggers have been suggested as contributing to this increasing trend $[1,2]$. In spite of the introduction of new potential treatments, diabetes and related complications continue to be a major medical problem. The possibility of strong side effects associated with the current pre-clinical protocols developed in rodents is a major concern and unacceptable in humans [3].

Recently, the role of herbal remedies has come into focus due to the side effects associated with current protocols in the treatment and containment of diabetes and its associated complications. More than 400 plants with glucose-lowering effects are known in India [4], some of which have been tested and their active components are being isolated. Thus, there is continuing search for new anti-diabetic drugs.

Cinnamon is one of the traditional herbs used as a remedy for diabetes. Cinnamon tree (Cinnamomum zeylanicum B. Lauraceae) is a native of South-west Asia, including Sri Lanka, and the bark is sold in powder, scrapings and branches. Cinnamon extract has also been shown to enhance glucose utilization in vivo in a dose-dependent manner, as well as potentiates insulinstimulated tyrosine phosphorylation of IR- $\beta$, insulin receptor-1 (IRS-1) and Insulin receptor substrate-1 (IRS-1) association with phosphotidyl inositol-3 kinase (PI 3-kinase), without affecting their protein content in skeletal muscle [5].

Cinnamon extract has a regulatory role in a type-2 diabetic animal model (C57BIKsj $\mathrm{db} / \mathrm{db}$ ). It was found to reduce blood glucose in a dose-dependent manner, as well as triglyceride, total cholesterol and intestinal $\alpha$ glycosidase activity, but enhances serum insulin and HDL-cholesterol levels. It also shows blood glucose-suppressing effect by improving insulin sensitivity or slowing absorption of carbohydrates in the small intestine [6].

Widespread achievement of therapeutic glycemic targets remains an elusive goal for type- 1 diabetic subjects. To date, only one study of the role of cinnamon in glycemic control among adolescents with type-1 diabetes has been reported [7]. In this context, the aim of the present study was to investigate new and strong evidence of the hypolipidemic and anti-diabetic activity of Cinnamomum zeylanicum aqueous bark extract in STZ-induced type-1 diabetic rats.

\section{EXPERIMENTAL}

\section{Plant material}

Cinnamon bark was purchased from an ayurvedic store in Kannur, Kerala, India in December 2008. The plant material was identified as per Auyervada literature, by a local expert in herbal gardens, and confirmed by Dr. H.S. Dhaliwal, Professor of Plant Biotechnology, Department of Biotechnology, Indian Institute of Technology, Roorkee, India.

\section{Preparation of the bark extract}

Cinnamon bark ( $500 \mathrm{~g})$ was thoroughly powdered and kept airtight in cool, dry and dark conditions. Approximately $50 \mathrm{~g}$ was placed in a soxhlet apparatus and extracted in aqueous medium for $60 \mathrm{~h}$. The extract was concentrated in a rotary evaporator at reduced pressure to give a yield of $10 \%$ which was then lyophilized (ScanVac CoolSafe Freeze Drying ${ }^{\mathrm{Tm}}$ ) and used for further studies.

\section{Experimental animals}

The study was conducted on 26 male Wistar rats, 8 - 10 weeks old, weighing $160-180 \mathrm{~g}$, and purchased from the animal facility centre 
at NIPER, Chandigarh, India. They were housed in colony cages (maximum 5 rats/cage) at an ambient temperature of $25 \pm$ $2{ }^{\circ} \mathrm{C}$ with $12 \mathrm{~h} / 12 \mathrm{~h}$ light/dark cycle. The rats were fed normal diet purchased from commercial vendors and were randomly divided into three groups $(n=6)$ : Group 1 (untreated, control); Group 2 (streptozotocininduced diabetic); and Group 3 streptozotocin-induced diabetic rats treated with the extract. The rats were acclimatized for a period of a further 2-3 weeks in the new environment prior to initiation of the experiment. The animals were deprived of food at least $16 \mathrm{~h}$ but were allowed free access to drinking water. All the experiments were performed as per the guidelines of the Institutional Animal Ethics Committee which also gave approval for the tests (registration number: 563/02/a/CPCSEA), and the national guidelines of Committee for the Purpose of Control and Supervision of Experiments on Animals, as applicable. The animals were handled according to the standard protocols for the use of laboratory animals [8].

\section{Induction of diabetes mellitus}

A freshly prepared solution of streptozotocin (65 mg/kg body weight) in $0.1 \mathrm{M}$ citrate buffer (pH 4.5) was injected intraperitoneally to the overnight fasted rats. The rats in the control group were injected with sodium citrate buffer (vehicle). Fasting blood glucose (FBG) was evaluated at the time of induction of diabetes while postprandial glucose (PPG) was checked regularly until stable hyperglycemia was achieved. The rats having marked hyperglycemia (FBG > $250 \mathrm{mg} / \mathrm{dl}$ ) were selected for the study as stable hyperglycemic animals [9].

\section{Serum preparation}

Serum was prepared following routine procedure. Briefly, blood samples were withdrawn from retro orbital sinus using nonheparinised capillary tubes, collected in dried centrifuge tubes and allowed to clot. Serum was separated from the clot by centrifugation for five $\min$ at $800 \times \mathrm{g}$ in a fixed rotor centrifuge at room temperature. The serum was collected carefully using a Pasteur pipette and kept at $-20{ }^{\circ} \mathrm{C}$ until enzyme analysis.

\section{Determination of lipid profile and tissue glycogen}

Total cholesterol, high density lipoprotein (HDL) cholesterol and triglyceride (TG) levels in serum were determined according to the instructions of the manufacturer (Transasia Bio Medical Limited, Himachal Pradesh, India). For the determination of very low density lipoprotein (VLDL) and low density lipoprotein (LDL) cholesterol, Friedwald's formulae was used which gives: VLDL cholesterol as triglyceride/ 5 , and LDL cholesterol as total cholesterol - (VLDL + HDL cholesterol). The assessment of tissue glycogen from liver was carried out by the method of Sadasivam [10]. The liver was homogenized in hot $80 \%$ ethanol to a tissue concentration of $100 \mathrm{mg} / \mathrm{ml}$ and then centrifuged at $8000 \times \mathrm{g}$ for $20 \mathrm{~min}$. The residue was collected and allowed to dry over a hot water bath. To the residue, $5 \mathrm{ml}$ of distilled water and $6 \mathrm{ml}$ of $52 \%$ perchloric acid was added, and the mixture subjected to extraction at $0{ }^{\circ} \mathrm{C}$ for $20 \mathrm{~min}$. The mixture was centrifuged at $8000 \times \mathrm{g}$ for $15 \mathrm{~min}$. The supernatant $(0.2 \mathrm{ml})$ was transferred to a graduated test tube and the volume made up to $1 \mathrm{ml}$ with distilled water. Graded standards were prepared using $0.1,0.2,0.4,0.6,0.8$ and $1.0 \mathrm{ml}$ of the working standard and the volume of each of these made up to $1 \mathrm{ml}$ with distilled water. To each of the test tubes, $4 \mathrm{ml}$ of anthrone reagent was added. The tubes were heated in a boiling water bath and then allowed to cool to room temperature. The intensity of the green to dark green colour of the solution generated was recorded spectrophotometrically at $630 \mathrm{~nm}$. The amount of glycogen was computed from calibration (standard) curve derived from standard glucose solution. The amount of glycogen in the tissue sample was expressed in $\mu \mathrm{g} / \mathrm{mg}$ tissue. 
Semi-quantitative reverse transcriptasepolymerase chain reaction $R T-P C R$

Total RNA were extracted from treated and diabetic rat liver and pancreas, respectively using GenElute ${ }^{T M}$ Mammalian Total RNA Miniprep Kit (Sigma-Aldrich, U.S.A). The isolated RNA samples were quantified, equal amounts of which were reverse transcribed with the aid of the RT-PCR kit (Bangalore Genei, Bangalore, India) according to manufacturer's instructions. PCR was performed by denaturing at $94{ }^{\circ} \mathrm{C}$ for $60 \mathrm{~s}$, annealing at various temperatures (depending on primer pairs) and by extension at $72{ }^{\circ} \mathrm{C}$ for $60 \mathrm{~s} ; 35$ additional cycles were used for amplification. The primer pairs used for analysis were: GK-F5'-CAGACAGTCCTCACCTGCAA-3',GK-R5'TTTGTCTTCACGCTCCACTG-3';G6Pase-F5'-ACCCTGGTAGCCCTGTCTTT-3', G6Pase-R5'-ACTCATTACACGGGCTGGTC-3'; Ins II-F5'-CTGTGGATCCGCTTCCTG-3', Ins II-R5'-AGAGAGAGCAGATGCTGGTG-3'; PEPCK-F5'-ATACGGTGGGAACTCACTGC-3',PEPCK-R5'-ACCCCCATCACTTGTCTCAG-3'; Gapdh-F5'AGACAGCCGCATCTTCTTGT-3', GapdhR5'-TACTCAGCACCAGCATCACC-3'. PCR product of $\beta$-Actin gene, using $\beta$-Actin-F5'CAGCGGAACCGCTCATTGCCAATGG-3', $\beta$ Actin-R5'-TCACCCACACTGTGCCCCATCTACGA-3' primers, was used as internal standard. The PCR products were then separated on $2 \%$ agarose gel and visualized in a gel documentation system (Bio Rad, USA). The intensity of the bands on gels was converted into a digital image with a gel analyzer.

\section{Statistical analysis}

All values are presented as mean \pm SEM (standard error of mean). Statistical significance was evaluated by independent two-population $t$-test using Origin software (Origin Lab Corporation, USA), version 6.1. $P$ $<0.05$ was taken as indicative of significant difference.

\section{RESULTS}

\section{Lipid profile}

There was a significant reduction $(p<0.05)$ of $12.5,23.86,14.96$ and $20 \%$ in TC, TG, LDLcholesterol and VDL-cholesterol levels, respectively, whereas a significant $(p<0.05)$ increase of HLD-cholesterol in diabetic rats by $25 \%$, as compared to their initial values (Table 1).

\section{Glycogen level in liver}

Tissue glycogen content showed a significant increase $(p<0.05)$ of $172.3 \%$, after oral administration of the extract in STZ-induced diabetic rats (Table 1).

\section{Gene expression profile}

As shown in Fig. 1, a marked change in

Table 1: Serum lipid levels and tissue glycogen content following administration of $C$. zeylanicum aqueous bark extract to streptozotocin-induced diabetic rats.

\begin{tabular}{|c|c|c|c|c|c|c|}
\hline \multirow{2}{*}{ Group } & \multicolumn{5}{|c|}{ Serum lipid level } & \multirow{2}{*}{$\begin{array}{l}\text { Tissue glycogen } \\
\text { content }(\mu \mathrm{g} / \mathrm{g})\end{array}$} \\
\hline & $\begin{array}{c}\mathrm{TC} \\
(\mathrm{mg} / \mathrm{dl})\end{array}$ & $\begin{array}{c}\text { HDLC } \\
\text { (mg/dl) }\end{array}$ & $\begin{array}{r}\text { LDL } \\
(\mathrm{mg} / \mathrm{dl})\end{array}$ & $\begin{array}{c}\text { TG } \\
(\mathrm{mg} / \mathrm{dl})\end{array}$ & $\begin{array}{c}\text { VLDL } \\
(\mathrm{mg} / \mathrm{dl})\end{array}$ & \\
\hline Normal & $141 \pm 3.8$ & $400+21$ & $78 \pm 3.1$ & $113 \pm 3.7$ & $23 \pm 1.9$ & $49.5 \pm 3.4$ \\
\hline Diabetic & $208 \pm 8.2$ & $25.6 \pm 1.5$ & $147 \pm 7.4$ & $176 \pm 7.2$ & $35 \pm 1.4$ & $16.3 \pm 2.3$ \\
\hline Treated & $182 \pm 4.7^{*}$ & $32.0 \pm 2.8^{*}$ & $25 \pm 3.8^{*}$ & $134 \pm 6.6^{*}$ & $28 \pm 0.6^{*}$ & $44.3 \pm 3.4^{*}$ \\
\hline
\end{tabular}

Each value is mean \pm S.E.M., $n=6$; * statistically significant different compared to diabetic group ( $p<$ 0.05). 
expression profile of mRNA for all the glucose hepatic regulatory enzymes was observed in diabetic treated groups (Group $3)$. The hepatic level of glucokinase and glucose-6 phosphate dehydrogenase increased 2-fold in treated diabetic rats while pancreatic insulin II expression increased several-fold, compared to untreated diabetic rats. Furthermore, there was a clear reduction in the expression patterns of gluconeogenic enzymes, G6Pase and PEPCK, by almost 2-fold, compared to diabetic rats (Group 2). In contrast, hepatic $\beta$ Actin showed uniform expression in all the groups - normal, diabetic and treated animals.
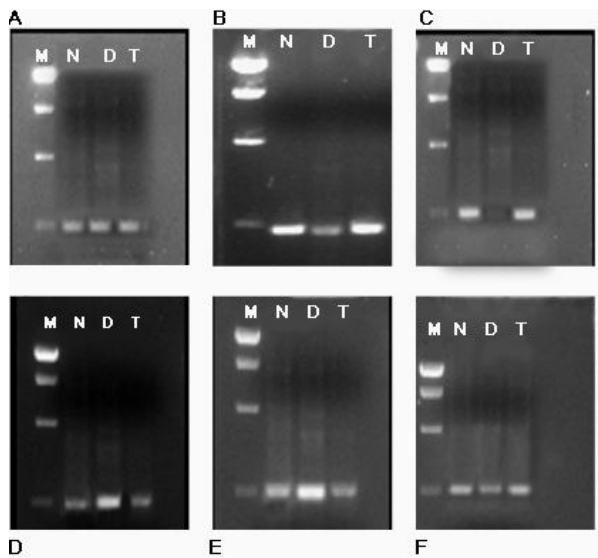

Fig 1: RT-PCR analysis of (A) liver mRNA expression of alpha actin, (B) liver mRNA expression of glucokinase, (C) liver mRNA expression of glucose-6-phosphate dehydrogenase, (D) liver mRNA expression of glucose-6-phosphatase, (E) liver mRNA expression of phosphoenol pyruvate carboxykinase, and (F) pancreas mRNA expression of Insulin II, before and after treatment of extract in diabetic rats. Note: M, N, D and T denote DNA ladder, normal, diabetic and treated diabetic samples of RNA from liver and pancreas, respectively

\section{DISCUSSION}

Streptozotocin has been shown to induce free radical production and cause tissue injury. The pancreas is especially susceptible to the action of streptozotocin-induced free radical damage. It was reported earlier that cinnamon extract is capable of acting as a free radical scavenger in vitro [11]. A single intraperitoneal injection of streptozotocin (65 $\mathrm{mg} / \mathrm{kg}$ ) induced damage that mimicked insulin-dependent diabetic (T1DM) conditions to a great extent. The present study was designed to determine the lipid profile, tissue glycogen content and glycolytic, gluconeogenic gene expression profile in both diabetic (control) and treated rats.

In order to understand the molecular mechanism of action of Cinnamomum zeylanicum aqueous extract as antidiabetogenic agent, the expression level of glucokinase, glucose-6-phosphatase, glucose -6-phosphate dehydrogenase, Insulin II and phosphoenol pyruvate carboxykinase was analyzed. These enzymes are directly linked to glucose homeostasis and production of glycogen. Glucokinase is involved in the phosphorylation step of glucose during glycolysis. This enzyme was significantly reduced in the liver of diabetic rats and this may be the reason for the decrease in the utilization of glucose and increased blood glucose level [12]. The extract-treated diabetic rats showed increased activity of glucokinase that may lead to activation of glycolysis and increased utilization of glucose for energy production. Glucokinase that that leads to a reduction in the expression of G6Pase and PEPCK in response to extract treatment provides an additional clue to its role in carbohydrate metabolism [13]. The extract-treated diabetic rats showed increased expression of insulin II, compared to diabetic control. This is another possible reason for the normal blood glucose levels in extract-treated diabetic group.

Glucose-6-phosphate dehydrogenase (G-6$\mathrm{PDH}$ ) is the key enzyme for maintaining normal blood sugar level. Streptozotocininduced type-1 diabetes also develops due to reduction of G-6-PDH activity in the liver which obstructs glucose utilization via pentose phosphate pathway as this enzyme activity is under insulin stimulation [14]. The 
expression of G-6-PDH increased after oral administration of the extract. These results clearly show the vibrant role of the extract in restoring the glucose homeostasis in STZinduced diabetic rats.

Cardiovascular diseases are listed as the cause of death in $65 \%$ of people suffering from diabetes [15]. Since lipid abnormalities accompanied with premature atherosclerosis are the major cause of cardiovascular diseases in diabetic patients, an ideal treatment for diabetes, in addition to glycemic control, should seek to achueve a favorable lipid profile. There was a significant decrease in TC, LDL, VLDL and TG levels as well as enhancement of the cardioprotective lipid, HDL, by $25 \%$ in diabetic rats following extract treatment (Table 1). Increase in HDLcholesterol is associated with a decrease in coronary risk and most of the drugs that decrease total cholesterol also decrease HDL-cholesterol [16]. In the present study, the extract not only decreased total cholesterol but also enhanced HDLcholesterol significantly.

High levels of TC and, more importantly, LDL cholesterol are major coronary risk factors [17]. Administration of the extract to diabetic rats lowered TC and LDL cholesterol by 12.5 and $15 \%$, respectively. This is remarkable as diabetes is associated with coronary complications which constitute the major cause of morbidity and deaths in diabetic subjects. Biochemical studies suggest that TG itself is independently related to coronary heart disease [18] and most of the antihypercholesterolemic drugs do not decrease TG levels but the extract lowered it by $23.9 \%$ after treatment. The level of glycemic control is the major determinant of very low density lipoprotein and triglyceride concentrations [19]; improved glycemic control following extract treatment also resulted in decreased levels of serum VLDL and total triglyceride. This progressive change in lipid profile of the treated diabetic rats sheds some light on the mode of action of the extract as a positive stimulator of lipid homeostasis in streptozotocin-induced type-I diabetic rats.

Glycogen is the primary intracellular storable form of glucose and its levels in liver is a direct reflection of insulin activity. Since streptozotocin causes selective destruction of $\beta$-cells of islets of Langerhans, resulting in marked decrease in insulin levels, it could be predicted that glycogen levels in liver decrease as the influx of glucose in the liver is inhibited in the absence of insulin [20]. Our study showed that the extract significantly improved hepatic glycogen levels in treated diabetic rats. This suggest thats one of the possible ways the extract exerts its effect is by improving the process of glycogenesis in liver.

\section{CONCLUSION}

The aqueous bark extract of $C$. zeylanicum exhibits strong hypolipidemic activity in addition to its role in glucose homeostasis in diabetic animals. We believe that our findings brings forth new and strong evidence that the bark extract, if used as a glucose homeostatic agent, may also reverse dyslipidemia associated with type-1 diabetes and prevent cardiovascular complications which are prevalent in diabetic patients. Thus, there is need for further investigation of this extract with a view to the development of potent phytomedicine for type-1 diabetes mellitus from Cinnamomum zeylanicum.

\section{ACKNOWLEDGEMENT}

Financial assistance to one of the authors, Syed Asif Hassan, in the form of a research fellowship from Ministry of Environment and Forests, Government of India, is gratefully acknowledged.

\section{REFERENCES}

1. Gale EA. Spring harvest? Reflections on the rise of Type 1 diabetes. Diabetologia 2005; 48: 24452450. 
2. Peng $H$, Hagopian W. Environmental factors in the development of Type 1 diabetes. Rev Endocr Metab Disord 2006; 7: 149-162.

3. Von Herrath MG, Nepom GT. Lost in translation: barriers to implementing clinical immunotherapeutics for autoimmunity. J Exp Med 2005; 202 (9): 1159-1162.

4. Grover JK, Yadav S, Vats V. Medicinal plants of India with anti-diabetic potential. J Ethnopharmacol 2002; 81: 81-100.

5. Qin B, Nagasaki M, Ren M, Bajotto G, Oshida Y, Sato Y. Cinnamon extract (traditional herb) potentiates in vivo insulin-regulated glucose utilization via enhancing insulin signaling in rats. Diabetes Res Clin Pr 2003; 62: 139-148.

6. Kim HSH, Choung SY. Anti-diabetic effect of cinnamon extract on blood glucose in $d b / d b$ rats. J Ethnopharmacol 2006; 104: 119-123.

7. Justin AA, Samuel JC, Todd AM, Kevin MC. The Effect of Cinnamon on A1C among Adolescents with Type 1 Diabetes. Diabetes Care 2007; 30: 813- 816.

8. National Institute of Health, USA. Public health service policy on humane care and use of laboratory animals; 2002.

9. Kenneth KW, Youming H. Streptozotocin-Induced Diabetic Models UNIT 5.47 in Mice and Rats, Current Protocols in Pharmacology, 2008; 5.47.1-5.47.14.

10. Sadasivam S, Manikam A. Carbohydrates. In: Sadasivam S; Manickam A. Methods in biochemistry. New Delhi: New Age International Pvt. Ltd. 1996; pp 11-12.

11. Mathew S, Abraham TE. Studies on the antioxidant activities of cinnamon (Cinnamomum verum) bark extracts, through various in vitro models. Food Chem 2006; 94: 520-528.

12. Vestergaard H. Studies of gene expression and activity of hexokinase, phosphofructokinase and glycogen synthase in human skeletal muscle in states of altered insulin-stimulated glucose metabolism. Dan Med Bull 1999; 46: 13-34.

13. Bhavna S, Viswanath G, Rajani S, Partha R. Effects of flavonoid-rich extract from seeds of Eugenia jambolana (L.), on carbohydrate and lipid metabolism in diabetic mice Food Chem 2008; 110: 697-705.

14. Ugochukw, NH, Babady N.E. Antihyperglycemic effect of aqueous and ethanolic extract of Gongronema latifolium leaves on glucose and glycogen metabolism in liver of normal and streptozotocin-induced diabetic rats. Life Sci 2003; 73: 1925-1938.

15. Geiss LS, Herman WH, Smith PJ. Diabetes in America. National Institutes of Health, National Institute of Diabetes and Digestive and Kidney Diseases, Bethesda; 1995. pp. 233-257.

16. Wilson PWF. High density lipoprotein, low density lipoprotein and coronary heart disease. $A m \mathrm{~J}$ Cardiol 1990; 66: 7A-10A.

17. National Cholesterol Education Program Expert Panel. Second report of the expert panel on detection, evaluation and treatment of high blood cholesterol in adults Circulation. 1994; 89: 1329-1450.

18. Bainton $D$, Miller NE, Botton $C H$, Yarnell JWG, Suretman PM, Baker IA, Lewis B, Elwood PC. Plasma triglycerides and high density Lipoprotein cholesterol as predictors of ischemic heart disease in British man. Brit Heart J 1992; 68: 60-66.

19. Taskinen MR. Beltz WF, Harper I. Effects of noninsulin dependent diabetes mellitus on VLDL triglyceride and apolipoprotein B metabolism: studies before and after sulfonylurea therapy. Diabetes 1986; 35: 1268-1277.

20. Golden S, Wals PA, Okakima F. Glycogen synthesis by hepatocytes from diabetic rats. Biochem J 1979; 182 (3): 727-734. 